BENTHAM OPEN
CrossMark
Content list available at: www.benthamopen.com/TODENTJ/
DOI: $10.2174 / 1874210601610010261$

\title{
Chronic Maxillary Sinusitis Caused by Denture Lining Material
}

\author{
Tsutomu Sugiura ${ }^{1,2,}$, Kazuhiko Yamamoto ${ }^{2}$, Chie Nakashima ${ }^{1,2}$, Kazuhiro Murakami ${ }^{2}$, Yumiko \\ Matsusue $^{2}$, Satoshi Horita ${ }^{2}$, Go Sakagami ${ }^{3}$ and Tadaaki Kirita ${ }^{2}$ \\ ${ }^{I}$ Department of Oral and Maxillofacial Surgery, Narakasuga Hospital, Nara, Japan \\ ${ }^{2}$ Department of Oral and Maxillofacial Surgery, Nara Medical University, Nara, Japan \\ ${ }^{3}$ Department of Otolaryngology, Nara City Hospital, Nara, Japan
}

Received: February 02, 2016

Revised: April 27, 2016

Accepted: May 03, 2016

\begin{abstract}
We report a case of chronic maxillary sinusitis caused by denture lining material entering through an oroantral fistula after tooth extraction. The patient was an 80 -year-old female who visited us with a complaint of pus discharge from the right posterior maxilla. She had extraction of the upper right second molar and had her upper denture relined with silicone lining material. The patient noticed swelling of the right cheek and purulent rhinorrhea 20 days before her first visit to our clinic. Oral examination showed an oroantral fistula with a diameter of $3 \mathrm{~mm}$ in the posterior alveolar ridge of the right maxilla. Computed tomography revealed a hyperdense foreign body in the right maxillary sinus and thickening of the mucosal lining. Under diagnosis of maxillary sinusitis caused by a foreign body, endoscopic maxillary surgery was performed simultaneously with the removal of the foreign body. The foreign body removed was $12 \times 6 \mathrm{~mm}$ in size, oval in shape, light pink in color, and compatible with silicone denture lining material. During the follow-up it was observed that the oroantral fistula closed spontaneously after the removal of the foreign body. The maxillary sinus was in a good shape without recurrence of sinusitis seven months after surgery.
\end{abstract}

Keywords: Denture lining material, Endoscopic surgery, Foreign body, Maxillary sinusitis.

\section{INTRODUCTION}

Maxillary sinusitis is occasionally odontogenic because of the anatomic juxtaposition of the teeth and maxillary sinus. Odontogenic sources once accounted for approximately 10 to $12 \%$ of all maxillary sinusitis cases [1]. However, in recent publications, up to $30 \%$ to $40 \%$ of such cases have been attributed to dental causes such as an oroantral fistulae, foreign bodies, and periapical/periodontal lesions [2,3]. Maxillary sinusitis secondary to the presence of foreign bodies is an unusual clinical complication [4]. Most foreign bodies, such as roots of teeth, root-filling materials, dental implants, and dental impression materials, are related to iatrogenic dental manipulation and/or the presence of an oroantral fistula [5 - 9].

Small foreign bodies in the maxillary sinus can be expelled spontaneously, but in most cases they require removal because they may cause chronic sinusitis [9]. A variety of techniques have been reported for the removal of foreign bodies such as endoscopic surgery and an intraoral direct approach through the anterior maxillary wall. In some cases, a combination of these approaches is necessary [6]. Therefore, the best treatment should be chosen according to the size and location of the foreign body and the condition of the maxillary sinus.

This paper reports a rare case of chronic maxillary sinusitis caused by denture lining material entering through an oroantral fistula, which was successfully treated endoscopically.

\footnotetext{
* Address correspondence to this author at the Department of Oral and Maxillofacial Surgery, Nara Medical University, 840 Shijo-cho, Kashihara City, Nara 634-8522, Japan; Tel/Fax: +81-744-29-8875; E-mail: sugiurat@naramed-u.ac.jp
} 


\section{CASE REPORT}

An 80-year-old female was referred to the Department of Oral and Maxillofacial Surgery, Narakasuga Hospital because of pus discharge from an oroantral fistula at the right posterior maxilla. The right upper second molar had been extracted 43 days before because of chronic periodontitis. She noticed swelling of the right cheek, purulent rhinorrhea, and discharge through the oroantral fistula 20 days before. She was prescribed antibiotics for seven days by her family doctor. The cheek swelling improved, but the discharge through the oroantral fistula persisted. She had a medical history of hypertension and chronic hepatitis $\mathrm{C}$, both of which were well controlled with an angiotensin II receptor blocker, calcium channel blocker, and ursodeoxycholic acid. The right chronic maxillary sinusitis was identified in Xray findings by her family doctor several years ago. However, it was asymptomatic and was not treated. A physical extra-oral examination was unremarkable. Oral examination revealed an oroantral fistula with a diameter of $3 \mathrm{~mm}$ in the posterior alveolar ridge of the right maxilla (Fig. 1). By irrigation of the right maxillary sinus through the oroantral fistula, purulent discharge was observed through the fistula.

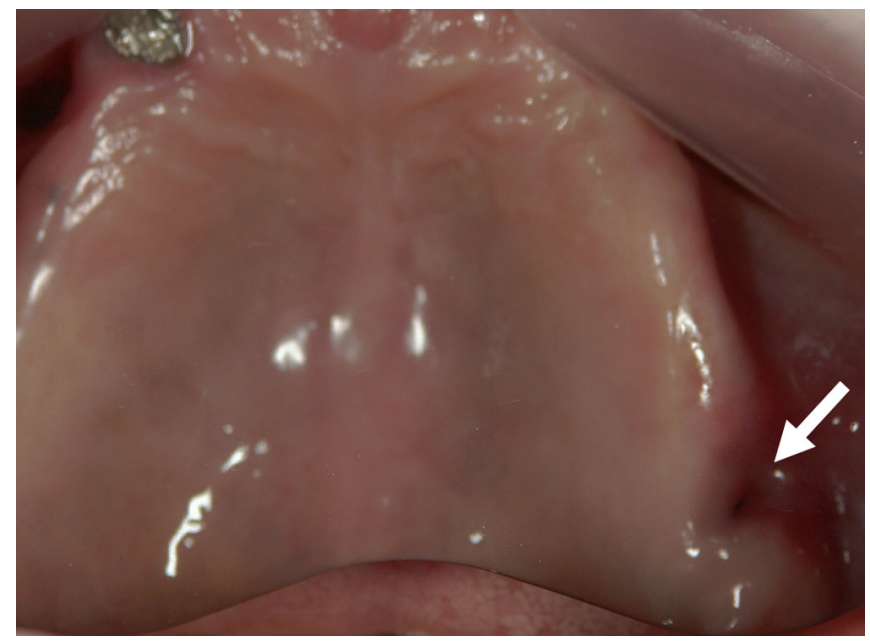

Fig. (1). Intraoral findings at the first visit. An oroantral fistula was observed at the posterior alveolar ridge of the right maxilla (mirror image).

A panoramic radiograph showed a bone defect at the posterior alveolar ridge of the right maxilla (Fig. 2). Computed tomography (CT) showed partial thickening of the mucosal lining and the presence of a hyperdense foreign body with a density of 240 Hounsfield units in the posterior lower part of the right maxillary sinus (Fig. 3). The patient was unaware of the presence of the foreign body. Because the upper complete denture was repaired with acrylic resin and relined with silicone soft lining material 36 days before (seven days after the tooth extraction), the foreign body was suspected to be the denture lining material.

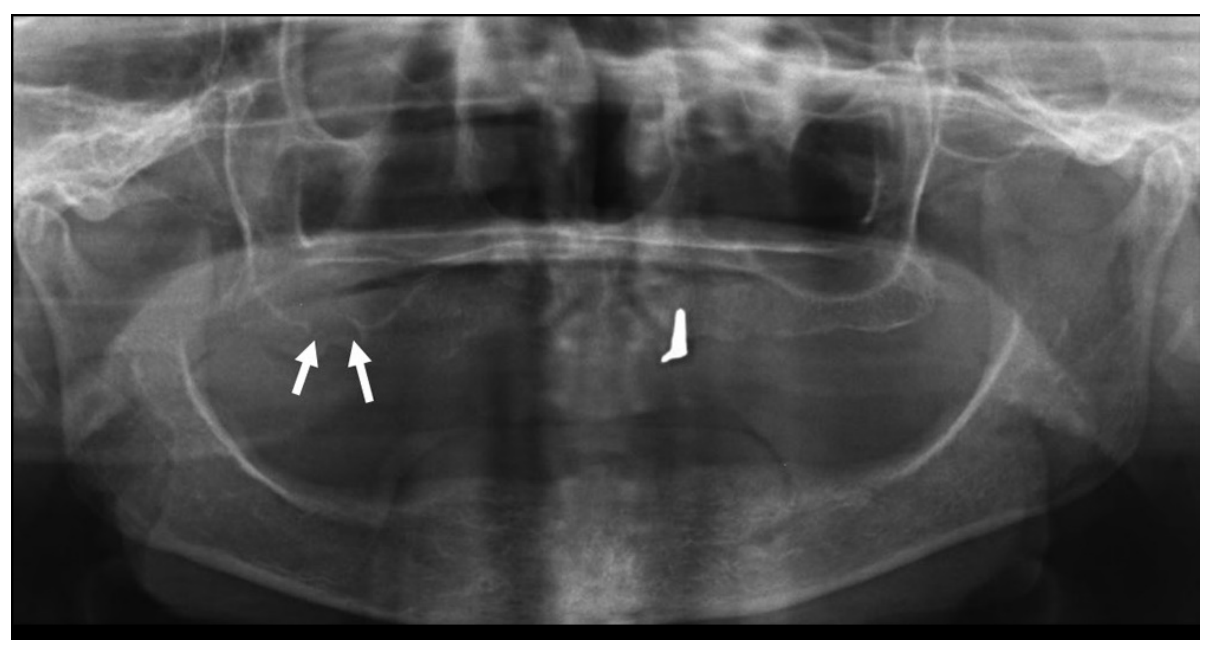

Fig. (2). Panoramic radiograph at the first visit. A bone defect was observed at the posterior alveolar ridge of the right maxilla. 

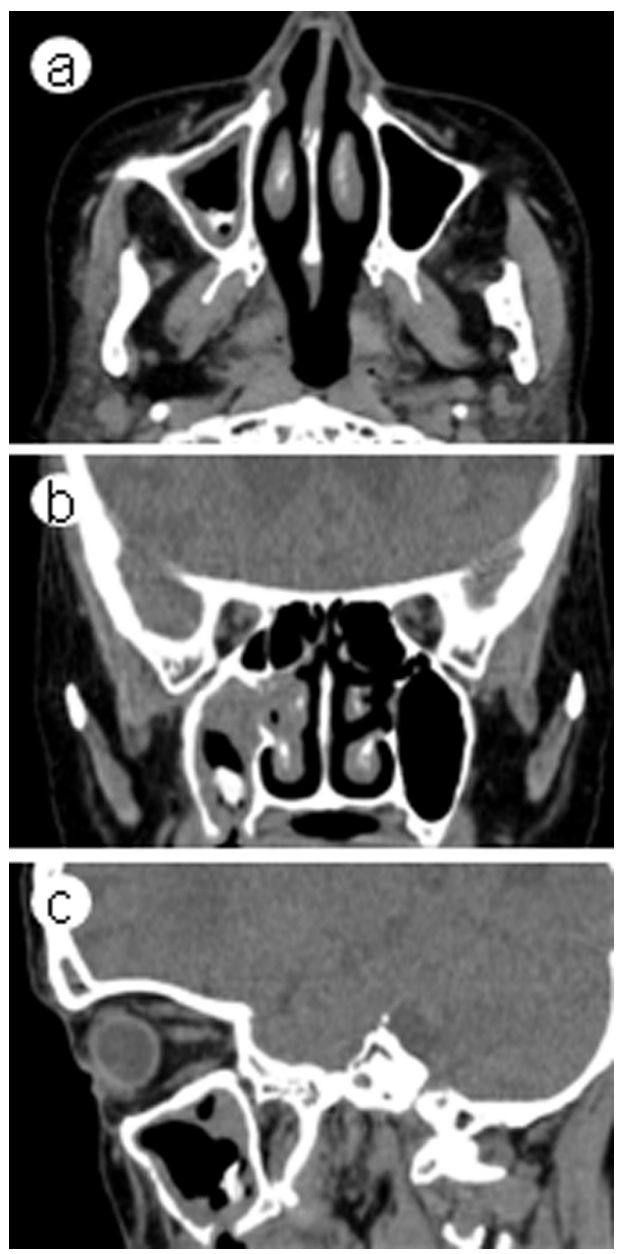

Fig. (3). CT scans at the first visit. Partial thickening of the mucosal lining and a hyperdense foreign body in the right maxillary sinus were observed. (a) axial plane, (b) coronal plane, (c) sagittal plane.

Antibiotic therapy with cefditoren pivoxil was conducted for seven days. The oroantral fistula became almost closed. The patient refused to undergo immediate surgical treatment. Low dose macrolide was administered to improve the maxillary sinusitis for a month. However, CT examination showed complete opacification in the maxillary, ethmoid and frontal sinuses on the right side (Fig. 4).

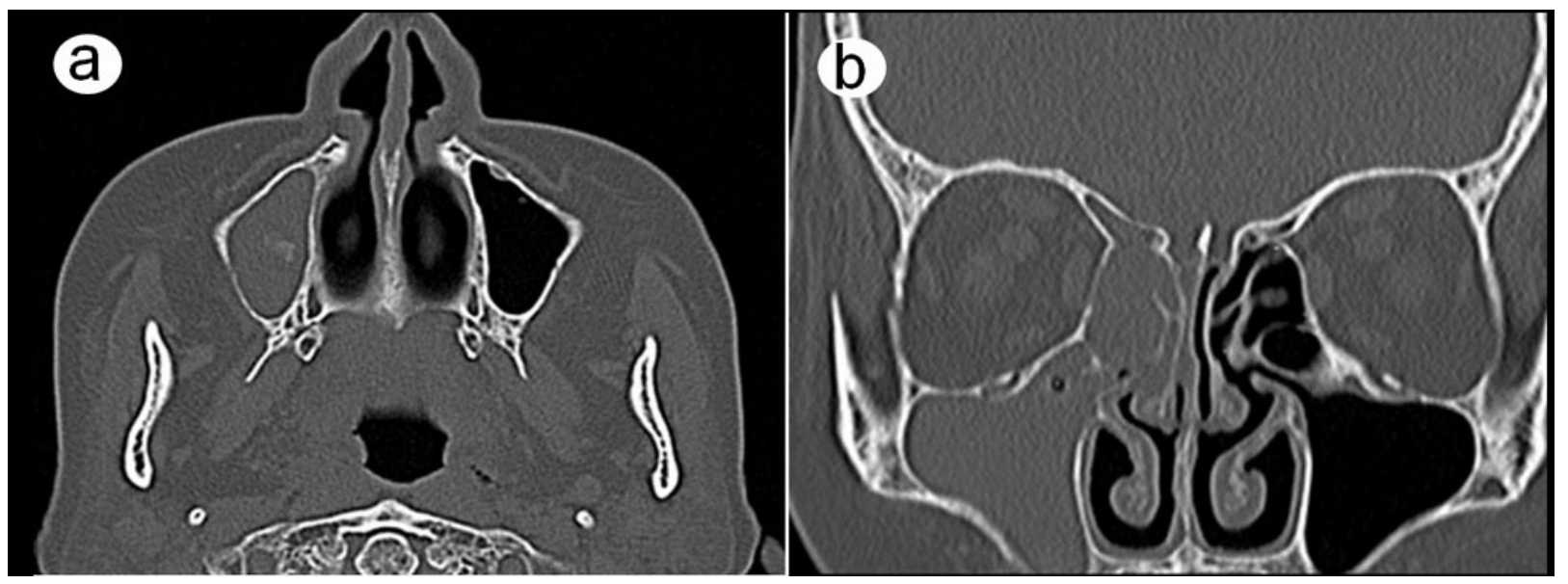

Fig. (4). CT scans 6 weeks after the first visit. Complete opacification in the maxillary, ethmoid and frontal sinuses on the right side was observed. (a) axial plane, (b) coronal plane. 
The foreign body was removed by endoscopic surgery under general anesthesia 11 weeks after the first visit, and maxillary antrostomy and ethmoidectomy were also performed. First, the maxillary antrostomy was performed. The maxillary sinus was filled with inflamed hypertrophic mucosa and granulation tissue. The foreign body was found and removed endoscopically (Fig. 5). After removal of the granulation tissue, markedly inflamed mucous membrane was removed and the residual mucous membrane was irrigated and preserved. Then, anterior ethmoidectomy and revision of the frontal recess were performed. The foreign body was $12 \times 6 \mathrm{~mm}$ in size, oval in shape, light pink in color, and compatible with silicone soft lining material (Fig. 6).

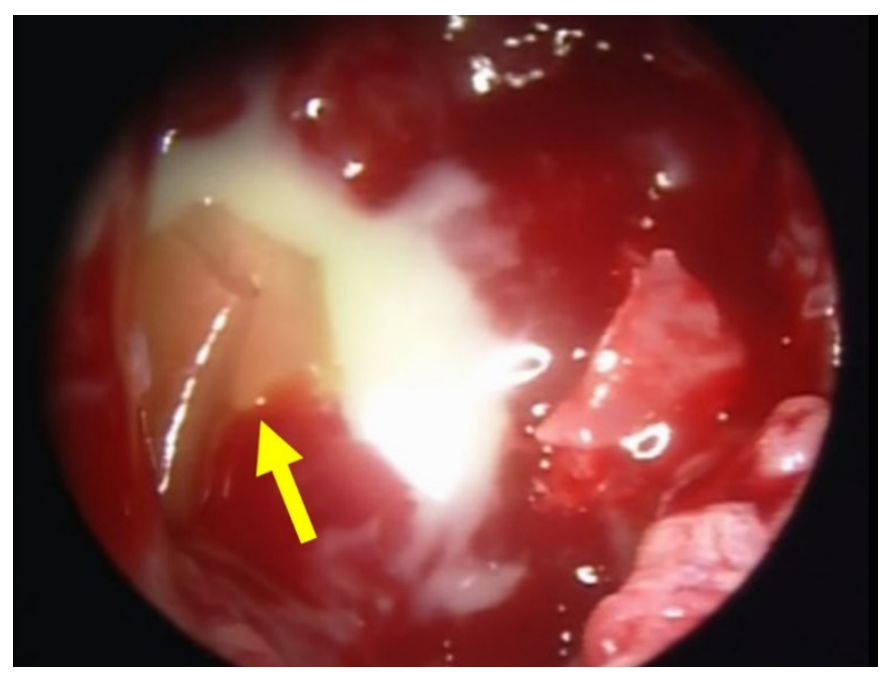

Fig. (5). Intra-operative endoscopic image. Inflamed hypertrophic mucosa and a foreign body (arrow) were observed.

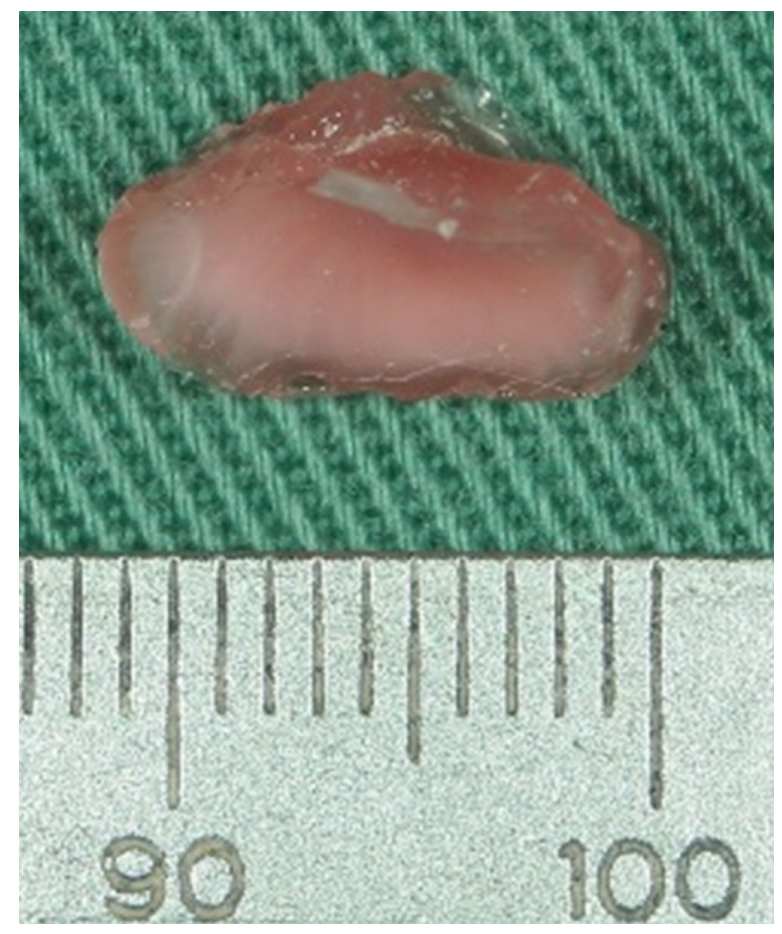

Fig. (6). The foreign body removed.

The oroantral fistula closed spontaneously four weeks after the surgery (Fig. 7). Macrolide antibiotics were administered for six months. The postoperative course was uneventful. After seven months of follow-up, CT scanning showed complete aeration of the right maxillary sinus (Fig. 8). 


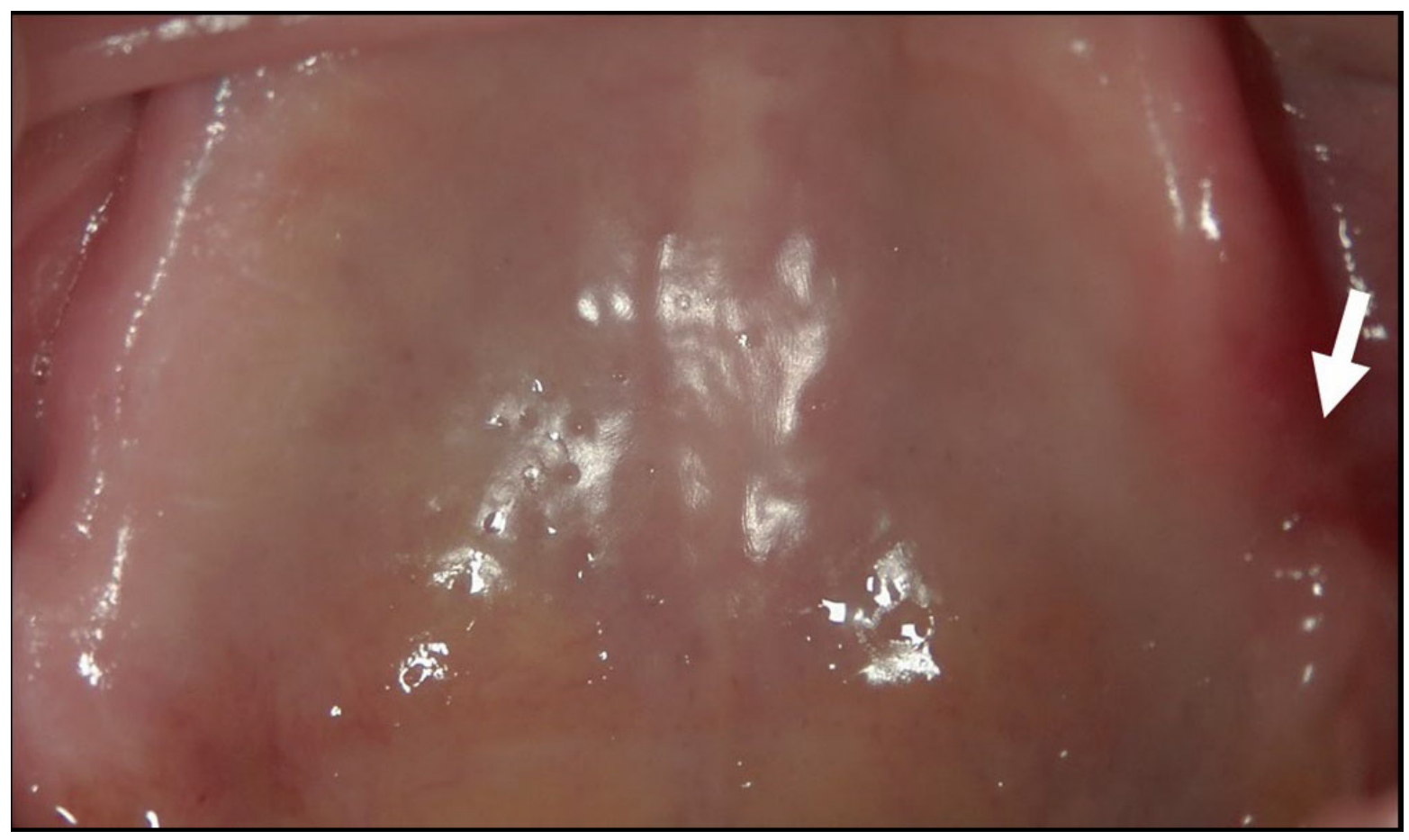

Fig. (7). Intraoral findings 4 weeks after surgery (mirror image). The oroantral fistula closed spontaneously.

We report a case of maxillary sinusitis caused by denture lining material entering through an oroantral fistula, which was successfully treated with endoscopic surgery. This case calls attention to an unusual cause of maxillary sinusitis related to dental manipulation.

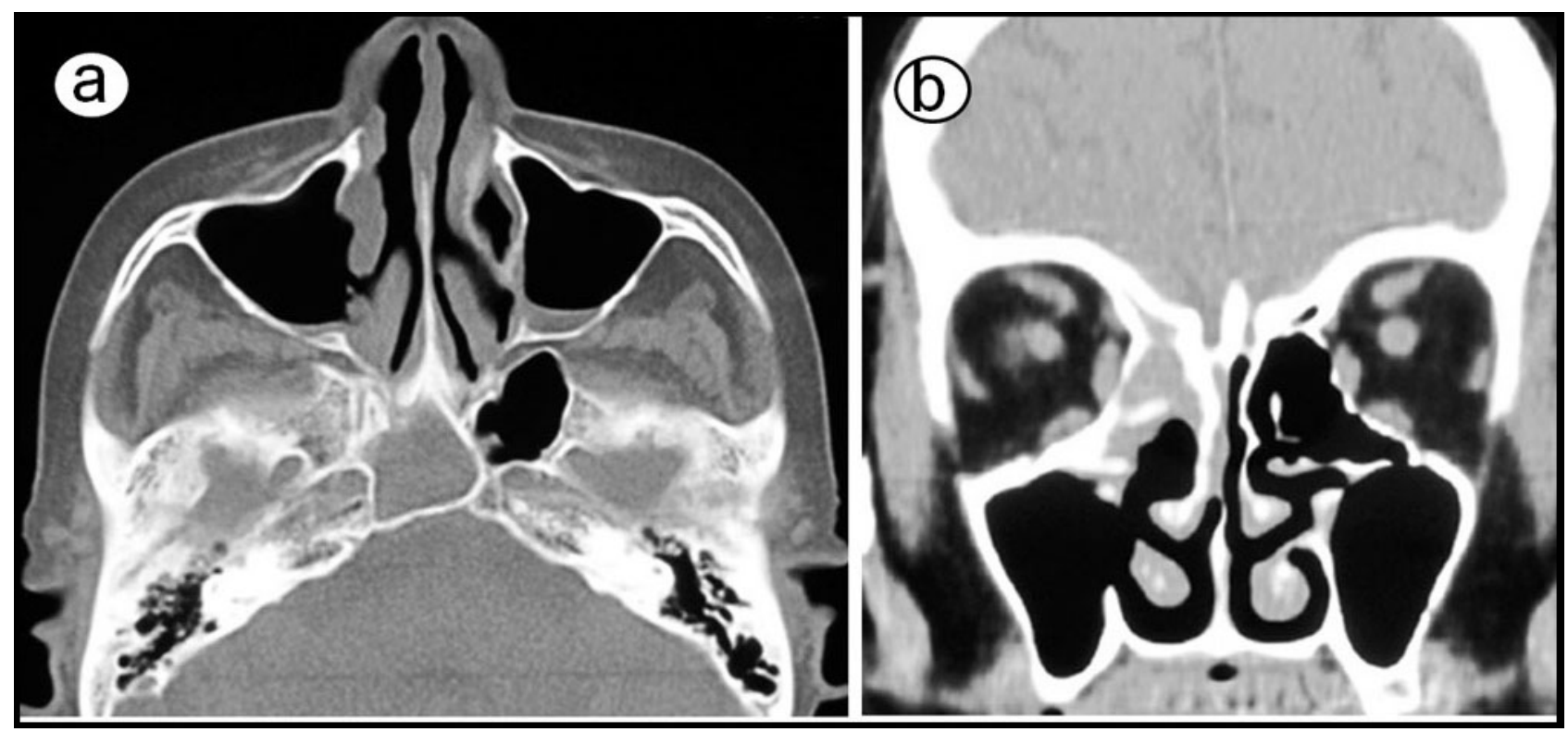

Fig. (8). CT scans 7 months after surgery. (a) axial plane, (b) coronal plane.

\section{DISCUSSION}

Sinonasal foreign bodies are seldom found in clinical practice. The most commonly found foreign bodies are displaced fractured roots of teeth and in some instances displaced whole teeth [5]. Other foreign bodies include dental burs, root-filling material, amalgam, needles, dental implants, and impression material [5 - 10]. Foreign bodies can get into the maxillary sinus due to trauma or accidentally during dental or surgical treatment. To our knowledge, there are no reports of maxillary sinusitis caused by silicone soft lining material entering through an oroantral fistula. An 
oroantral fistula is a well-documented postoperative complication associated with the extraction of maxillary molar and premolar teeth. However, it may be small and undetectable immediately after tooth extraction if the Valsalva test [11] is not performed [8], and therefore it may be left unrecognized for several weeks. The present case is a rare example of a foreign body in the maxillary sinus, as it is considered that silicone soft lining material entered into the maxillary sinus through the fistula in its plastic form during a denture relining procedure without being noticed.

Foreign bodies in the paranasal sinuses may cause inflammation/sinusitis by interrupting mucociliary clearance [12]. Further, in a case of acrylic resin, its presence in the oral cavity or the paranasal sinuses can increase the risk of aspiration pneumonia because acrylic resin is easily colonized and deeply infected due to its porosities [13]. In the present case, it is considered that the preexisting maxillary sinusitis was aggravated by the presence of the silicone soft lining material, and it probably spread through the whole maxillary sinus and to the ethmoid and frontal sinuses.

Although some authors argue that foreign bodies encapsulated under the sinus mucosa do not need surgery, the removal of foreign bodies is generally recommended to prevent infectious complications [14]. Various surgical techniques have been reported for the removal of a foreign body from maxillary sinuses, such as endoscopic surgery and an intraoral direct approach through the anterior maxillary wall.

The transoral endoscopic approach through the anterior maxillary wall is useful for gaining access to the maxillary sinus, although it is limited in cases without sinusitis and those with a small foreign body because of the limited visual field and accessibility [7]. This procedure can be performed under local anesthesia. The transnasal endoscopic approach to the maxillary sinus is minimally invasive and also allows simultaneous treatment of hyperplastic, hypertrophic, or infected mucosa in a more conservative way [12]. Moreover, in cases with the maxillary sinusitis involving the ethmoidal and frontal sinuses, an endoscopic approach also allows simultaneous treatment of these lesions [12, 15]. The intraoral direct approach through the anterior maxillary wall, principally by means of the Caldwell-Luc procedure, is indicated when the foreign body is considerable in size or inaccessible using endoscopic techniques [7]. Although this approach can be applied in those maxillary sinusitis cases in which surgical removal of the affected mucosa is necessary, the procedure is more invasive compared with endoscopic surgery. In the present case, endoscopic surgery was chosen because this procedure was a minimally invasive way to manage the maxillary sinusitis having spread into the ethmoidal and frontal sinuses and to remove the foreign body.

An oroantral fistula is a relatively common complication in dentoalveolar surgery. Successful management depends largely on primary closure of the defect and adequate medical management. A defect smaller than 5 mm will usually heal spontaneously [16], as observed in the present case. If a defect is larger than $5 \mathrm{~mm}$, primary closure is indicated. Before closure of an oroantral fistula, it is imperative to eliminate any acute or chronic infection within the sinus.

We report a case of maxillary sinusitis caused by denture lining material entering through an oroantral fistula, which was successfully treated with endoscopic surgery. This case calls attention to an unusual cause of maxillary sinusitis related to dental manipulation.

\section{CONFLICT OF INTEREST}

The authors confirm that this article content has no conflict of interest.

\section{ACKNOWLEDGMENTS}

Declared none.

\section{REFERENCES}

[1] Brook I. Sinusitis of odontogenic origin. Otolaryngol Head Neck Surg 2006; 135(3): 349-55. [http://dx.doi.org/10.1016/j.otohns.2005.10.059] [PMID: 16949963]

[2] Patel NA, Ferguson BJ. Odontogenic sinusitis: an ancient but under-appreciated cause of maxillary sinusitis. Curr Opin Otolaryngol Head Neck Surg 2012; 20(1): 24-8.

[http://dx.doi.org/10.1097/MOO.0b013e32834e62ed] [PMID: 22157162]

[3] Costa F, Emanuelli E, Robiony M, Zerman N, Polini F, Politi M. Endoscopic surgical treatment of chronic maxillary sinusitis of dental origin. J Oral Maxillofac Surg 2007; 65(2): 223-8. [http://dx.doi.org/10.1016/j.joms.2005.11.109] [PMID: 17236925]

[4] Bodet Agustí E, Viza Puiggrós I, Romeu Figuerola C, Martinez Vecina V. Foreign bodies in maxillary sinus. Acta Otorrinolaringol Esp 2009; 60(3): 190-3.

[http://dx.doi.org/10.1016/S2173-5735(09)70127-9] [PMID: 19558905] 
[5] Kumar N, Bhutani H, Jain P, et al. Accidental entry of foreign body in maxillary sinus-a case report. Open J Stomatol 2015; 5: 1-5. [http://dx.doi.org/10.4236/ojst.2015.51001]

[6] Chiapasco M, Felisati G, Maccari A, Borloni R, Gatti F, Di Leo F. The management of complications following displacement of oral implants in the paranasal sinuses: a multicenter clinical report and proposed treatment protocols. Int J Oral Maxillofac Surg 2009; $38(12): 1273-8$. [http://dx.doi.org/10.1016/j.ijom.2009.09.001] [PMID: 19781911]

[7] González-García A, González-García J, Diniz-Freitas M, García-García A, Bullón P. Accidental displacement and migration of endosseous implants into adjacent craniofacial structures: a review and update. Med Oral Patol Oral Cir Bucal 2012; 17(5): e769-74. [http://dx.doi.org/10.4317/medoral.18032] [PMID: 22549685]

[8] Rodrigues MT, Munhoz ED, Cardoso CL, de Freitas CA, Damante JH. Chronic maxillary sinusitis associated with dental impression material. Med Oral Patol Oral Cir Bucal 2009; 14(4): E163-6. [PMID: 19333183]

[9] Dimitrakopoulos I, Papadaki M. Foreign body in the maxillary sinus: report of an unusual case. Quintessence Int 2008; 39(8): 698-701. [PMID: 19107258]

[10] Abe K, Beppu K, Shinohara M, Oka M. An iatrogenic foreign body (dental bur) in the maxillary antrum: A report of two cases. Br Dent J $1992 ; 173(2): 63-5$.

[http://dx.doi.org/10.1038/sj.bdj.4807941] [PMID: 1503836]

[11] Valsalva AM. De aure humana tractatus. $1^{\text {st }}$ ed. Bologna: Pisarri C 1704.

[12] Felisati G, Lozza P, Chiapasco M, Borloni R. Endoscopic removal of an unusual foreign body in the sphenoid sinus: an oral implant. Clin Oral Implants Res 2007; 18(6): 776-80. [http://dx.doi.org/10.1111/j.1600-0501.2007.01409.x] [PMID: 17868385]

[13] Urushibara Y, Ohshima T, Sato M, et al. An analysis of the biofilms adhered to framework alloys using in vitro denture plaque models. Dent Mater J 2014; 33(3): 402-14. [http://dx.doi.org/10.4012/dmj.2013-325] [PMID: 24882112]

[14] Lopatin AS, Sysolyatin SP, Sysolyatin PG, Melnikov MN. Chronic maxillary sinusitis of dental origin: is external surgical approach mandatory? Laryngoscope 2002; 112(6): 1056-9. [http://dx.doi.org/10.1097/00005537-200206000-00022] [PMID: 12160273]

[15] Crovetto-Martínez R, Martin-Arregui FJ, Zabala-López-de-Maturana A, Tudela-Cabello K, Crovetto-de la Torre MA. Frequency of the odontogenic maxillary sinusitis extended to the anterior ethmoid sinus and response to surgical treatment. Med Oral Patol Oral Cir Bucal 2014; 19(4): e409-13. [http://dx.doi.org/10.4317/medoral.19629] [PMID: 24608208]

[16] Simuntis R, Kubilius R, Vaitkus S. Odontogenic maxillary sinusitis: a review. Stomatologija 2014; 16(2): 39-43. [PMID: 25209225]

(C) Sugiura et al.; Licensee Bentham Open.

This is an open access article licensed under the terms of the Creative Commons Attribution-Non-Commercial 4.0 International Public License (CC BY-NC 4.0) (https://creativecommons.org/licenses/by-nc/4.0/legalcode), which permits unrestricted, non-commercial use, distribution and reproduction in any medium, provided the work is properly cited. 